\title{
High expression of enhancer of zeste homologue 2 indicates poor prognosis in patients with soft tissue sarcomas
}

\author{
KENSAKU YAMAGA ${ }^{1}$, MITSUHIKO OSAKI ${ }^{1,2}$, KAZUNORI KIDANI ${ }^{1}$, \\ KOHEI SHOMORI ${ }^{1}$, HARUHIKO YOSHIDA ${ }^{1}$ and HISAO ITO ${ }^{1}$ \\ ${ }^{1}$ Division of Organ Pathology, Department of Microbiology and Pathology, Faculty of Medicine, Tottori University; \\ ${ }^{2}$ Division of Molecular Genetics and Biofunction, Department of Biomedical Science, Tottori University \\ Graduate School of Medical Science, Yonago, Tottori 683-8503, Japan
}

Received May 5, 2008; Accepted June 18, 2008

DOI: 10.3892/mmr_00000004

\begin{abstract}
Enhancer of zeste homologue 2 (EZH2), a member of the polycomb group of genes, is associated with malignancy in several human cancers. The purpose of this study was to examine the association between EZH2 expression and clinicopathological factors as compared to $\mathrm{Ki}-67$ expression in human soft tissue sarcomas. Expression of EZH2 and Ki-67 was immunohistochemically determined in paraffin-embedded sections from 104 soft tissue sarcomas. High expression of both EZH2 and Ki-67 was significantly correlated with distant metastasis $(\mathrm{P}<0.01)$, histologic grade $(\mathrm{P}<0.01)$ and poor prognosis $(\mathrm{P}<0.01)$, but not with clinicopathological factors such as age, sex, and tumor location and size. Although EZH2 expression was significantly correlated with Ki-67 expression ( $\mathrm{rs}=0.65, \mathrm{P}<0.01)$, multivariate analysis showed that high expression of EZH2, but not of Ki-67, was an independent factor of poor prognosis (relative risk $=2.79 ; \mathrm{P}=0.02$ ). These data suggest that expression of EZH2 is a novel and reliable prognostic marker of human soft tissue sarcomas.
\end{abstract}

\section{Introduction}

Soft tissue sarcomas are relatively rare malignant mesenchymal tumors. They represent a heterogeneous group of malignant tumors with a wide spectrum in terms of histologic type and prognosis, and often display highly aggressive behavior with a tendency towards early metastasis. However, it is sometimes difficult to predict their malignant potential. Many clinicopathological factors have been studied in order to predict malignant potential such as tumor size, depth and histologic grade (1-3). Predicting the malignant potential of soft tissue

Correspondence to: Dr Kensaku Yamaga, Division of Organ Pathology, Department of Microbiology and Pathology, Faculty of Medicine, Tottori University, 86 Nishi-cho, Yonago, Tottori 683-8503, Japan

E-mail: yamake0921@grape.med.tottori-u.ac.jp

Key words: EZH2, Ki-67, soft tissue sarcoma, prognostic factor sarcomas is important because it confers improvements on the therapeutic decision-making process. Prognostic or biological markers have also been studied in soft tissue sarcomas, and a variety of molecules have been reported as being significant prognostic markers of the disease. These include Ki-67, PCNA, p53, P-gp, Rb, EGFR, survivin, TERT, cyclin A, AKT, FAS, hMSH protein, CD100, cyclin D1, VEGF, Glut-1, $\beta$-catenin, p-glycoprotein, HIF-1 $\alpha$, CD44, EGF-1R and ezrin (4-24). However, others such as MCM2, TP, COX-2, VEGF and HER2/neu have failed to act as prognostic markers (25-27).

Enhancer of zeste homologue 2 (EZH2) is a member of the polycomb group of genes and is involved in the regulation of cell cycle progression $(28,29)$. EZH2 expression declines upon tissue maturation and differentiation, and is associated with malignancy in several cancers, including prostate, breast, bladder and gastric cancers, cutaneous melanoma and lymphoma (30-41). Almost all of these are epithelial malignant tumors or carcinomas, with the exception of lymphoma. However, the clinicopathological importance of EZH2 expression in sarcomas has not as yet been reported.

In the present study, immunohistochemistry was used to examine the clinicopathological significance of EZH2 expression in soft tissue sarcomas as compared to Ki-67 expression, which has been found to be associated with the prognosis of the disease (4-11).

\section{Materials and methods}

Tissue specimens. All specimens were obtained from a total of 104 patients with soft tissue sarcomas of the extremities and trunk. Surgery was used to obtain 102 specimens, while two were instead obtained by biopsy as the patients had died of sepsis during chemotherapy and of lung metastasis of the sarcoma. Patients were selected from the records of the Division of Organ Pathology, Faculty of Medicine, Tottori University, Japan, and its affiliated teaching hospitals. Approval for the study was obtained from the Institutional Review Board of the Faculty of Medicine, Tottori University (approval no. 283). Surgery and biopsy had been undertaken between 1981 and 2007. Clinical information on age, sex, tumor location, tumor size, distant metastases and treatment (radiotherapy and/or chemotherapy) was obtained from the 
clinical files. Follow-up was successful in all of the patients. As preoperative treatment, 25 of the 104 had received radiotherapy (30-50 Gy) alone, 27 chemotherapy alone, and 13 both radiotherapy and chemotherapy.

All specimens were fixed in $10 \%$ buffered-formalin and embedded in paraffin wax. Serial sections, $4 \mu \mathrm{m}$ thick, were stained using hematoxylin and eosin, periodic acid-Schiff reaction and immunohistochemistry. A histologic diagnosis was established according to the World Health Organization (WHO) classification (42). Histologic grade was assigned according to the criteria of the FNCLCC/French system (43) based on necrosis, number of mitotic cells and the degree of tumor differentiation.

Immunohistochemistry. Paraffin-embedded tumor tissue specimens were cut into 4- $\mu \mathrm{m}$ sections then dewaxed in xylene, rehydrated through a graded series of ethanol solutions and rinsed in distilled water for $5 \mathrm{~min}$. For EZH2 immunostaining, antigens were retrieved in EDTA solution (10 mM, $\mathrm{pH} 8.0)$ using an autoclave (BS-235; Tomy, Japan) at $121^{\circ} \mathrm{C}$ for $10 \mathrm{~min}$. For Ki-67 immunostaining, antigens were incubated at $37^{\circ} \mathrm{C}$ for $20 \mathrm{~min}$ in trypsin solution $(0.1 \%$ trypsin and $0.1 \%$ $\mathrm{CaCl}_{2}$ in $0.05 \mathrm{M}$ Tris- $\mathrm{HCl}$ buffer, $\mathrm{pH}$ 7.6) and were retrieved in $0.01 \mathrm{M}$ citrate buffer ( $\mathrm{pH}$ 6.0) using a microwave oven (MI-77; Azumaya, Japan) at $95^{\circ} \mathrm{C}$ for $20 \mathrm{~min}$. Endogenous peroxidase activity was blocked by $2 \%$ hydrogen peroxide in methanol at room temperature for $30 \mathrm{~min}$. After rinsing with PBS, the sections were incubated with blocking serum ( $2 \%$ fetal bovine serum) at room temperature for $20 \mathrm{~min}$ and incubated at $4^{\circ} \mathrm{C}$ overnight with each primary antibody. The following mouse monoclonal antibodies were used for immunohistochemistry: mouse monoclonal antibody against EZH2 (clone 11; BD Biosciences, USA; diluted 1:25) and Ki-67 monoclonal antibody (clone MIB-1; Dako, Denmark; diluted 1:50). A reaction was subsequently initiated by the streptavidinbiotin-peroxidase complex technique (SAB method) using a Histofine SAB-PO(M) Immunohistochemical Staining Kit (Nichirei, Japan). The immunoreaction was visualized with 3,3'-diaminobenzidine and $100 \mu 1$ hydrogen peroxide in $0.05 \mathrm{M}$ Tris- $\mathrm{HCl}$ buffer ( $\mathrm{pH}$ 7.6). Finally, the sections were counterstained with $0.1 \%$ hematoxylin.

Evaluation of immunohistochemical findings. To evaluate EZH2 and Ki-67 expression levels, positive tumor cell nuclei were counted in the most frequently and distinctly labeled areas. Counts were performed in high-magnification fields using the FLOVEL Image Filing System FlvFs (Flovel, Japan). The percentage of positive cells was determined for each antibody by two of the authors (K.Y. and K.S.), who were unaware of patient clinical data or the pathological diagnosis of the tumors. At least 1000 tumor cells for each antigen were counted in areas that showed a higher frequency of cells with nuclei positive for EZH2 and Ki-67. The labeling index (LI) was determined by counting the number of positive cells (expressed as a percentage). EZH2 and Ki-67 were categorized as showing high expression if the LI was equal to or greater than the median LI (EZH2 $=10.8 \%$ and $\mathrm{Ki}-67=5.6 \%)$. To confirm the specificity of the immunostaining results, sections immunoreacted without the primary antibodies were used as negative controls.
Statistical analysis. Statistical analysis was performed using Excel 2003 (Microsoft, USA) with the add-on software Statcel version 2 (OMS Publishing, USA) and StatView version 5.0 (Abacus Concept, USA). The Mann-Whitney U test was used in cases where there were two categorical variables of interest, and the Kruskal-Wallis test was used in cases with three or more variables. The correlation between EZH2 and Ki-67 expression was calculated using the Spearman rank order correlation test. Overall survival curves were calculated according to the Kaplan-Meier method. Univariate analysis was performed with the log-rank test, and multivariate analysis with a Cox proportional hazards regression model in a stepwise manner. Prognostic variables identified by backward elimination $(\mathrm{P}=0.20)$ were entered into a Cox proportional hazards regression model. Hazard ratios were reported with $95 \%$ confidence intervals $(\mathrm{CI})$. For all analyses, $\mathrm{P}<0.05$ was considered to be significant.

\section{Results}

The characteristics of the 104 patients with soft tissue sarcomas are shown in Table I. There were 64 men and 40 women with a mean age of 56.0 years (range $0.1-93$ years). The tumor was located at the extremities in 87 patients and on the trunk in 17. Tumor size was $>5 \mathrm{~cm}$ in 72 patients and $<5 \mathrm{~cm}$ in 32 . Distant metastases were present in 37 patients but absent in 67 . Of the 104 soft tissue sarcomas, histologic grades of 1,2 and 3 were diagnosed in 26, 49 and 29 cases, respectively. Tumors were histologically and immunohistochemically diagnosed as 36 malignant fibrous histiocytomas (MFHs)/undifferentiated pleomorphic sarcomas (UPSs), 6 myxofibrosarcomas, 31 liposarcomas, 14 synovial sarcomas, 9 leiomyosarcomas, 5 epithelioid sarcomas and 3 rhabdomyosarcomas.

EZH2 expression was observed in all the histologic types of soft tissue sarcoma examined. As shown in Fig. 1, EZH2 immunoreactivity was noted in tumor-cell nuclei. Table I shows the association of EZH2 and $\mathrm{Ki}-67$ expression with clinicopathological factors. The mean EZH2 and Ki-67 LIs were 14.9 and $9.4 \%$, respectively. There were significant correlations between the EZH2 and Ki-67 LIs and distant metastasis $(\mathrm{P}<0.01)$ and histologic grade $(\mathrm{P}<0.01)$. On the other hand, no correlation was observed between the EZH2 and Ki-67 LIs and other clinicopathological factors, including age, sex, tumor location and size. Among the histologic tumor types, the EZH2 LI was highest in rhabdomyosarcoma, followed by synovial sarcoma, epithelioid sarcoma, MFH/UPS, myxofibrosarcoma, leiomyosarcoma and liposarcoma. It was higher than the Ki-67 LI in all the histologic tumor types, except for myxofibrosarcoma.

Scattergrams of the correlation between the EZH2 and Ki-67 LIs are shown in Fig. 2. There was a positive correlation between the EZH2 and Ki-67 LIs, with a Spearman's correlation coefficient of $r s=0.65(\mathrm{P}<0.01)$. Thus, there was statistically significant evidence of the higher EZH2 and Ki-67 LIs.

Fig. 3 shows the Kaplan-Meier survival curves for EZH2 and Ki-67 expression in the 104 soft tissue sarcomas. Overall survival was significantly worse in patients with a higher EZH2 or Ki-67 LI than in those with a lower LI (EZH2, $\mathrm{P}<0.01$; Ki-67, $\mathrm{P}<0.01)$. Fig. 4 shows the Kaplan-Meier survival 
Table I. Characteristics and association of EZH2 and Ki-67 expression with clinicopathological factors in 104 soft tissue sarcomas.

\begin{tabular}{|c|c|c|c|c|c|}
\hline Variables & No. & EZH2 LI (mean) & P-value & Ki-67 LI (mean) & P-value \\
\hline All patients & 104 & 14.9 & & 9.4 & \\
\hline \multicolumn{6}{|l|}{ Age (mean 56.0 years) } \\
\hline$\geq 56$ years & 53 & 14.9 & NS & 9.9 & NS \\
\hline$<56$ years & 51 & 15.0 & & 8.9 & \\
\hline \multicolumn{6}{|l|}{ Sex } \\
\hline Male & 64 & 13.9 & NS & 8.4 & NS \\
\hline Female & 40 & 16.5 & & 11.0 & \\
\hline \multicolumn{6}{|l|}{ Tumor location } \\
\hline Extremity & 87 & 15.2 & NS & 9.7 & NS \\
\hline Trunk & 17 & 13.3 & & 7.7 & \\
\hline \multicolumn{6}{|l|}{ Tumor size } \\
\hline$\geq 5 \mathrm{~cm}$ & 72 & 14.6 & NS & 9.6 & NS \\
\hline$<5 \mathrm{~cm}$ & 32 & 15.6 & & 8.9 & \\
\hline \multicolumn{6}{|l|}{ Distant metastasis } \\
\hline Absent & 67 & 9.3 & $\mathrm{P}<0.01$ & 5.4 & $\mathrm{P}<0.01$ \\
\hline Present & 37 & 25.1 & & 16.6 & \\
\hline \multicolumn{6}{|l|}{ Histologic grade } \\
\hline Grade 1 & 26 & 5.0 & $\mathrm{P}<0.01$ & 1.9 & $\mathrm{P}<0.01$ \\
\hline Grade 2 & 49 & 15.2 & & 11.0 & \\
\hline Grade 3 & 29 & 23.2 & & 13.5 & \\
\hline \multicolumn{6}{|l|}{ Histologic type } \\
\hline MFH/UPS & 36 & 14.2 & & 11.5 & \\
\hline Pleomorphic & 31 & & & & \\
\hline Giant cell & 2 & & & & \\
\hline Inflammatory & 3 & & & & \\
\hline Myxofibrosarcoma & 6 & 10.1 & & 11.7 & \\
\hline Liposarcoma & 31 & 8.8 & & 3.9 & \\
\hline Well-differentiated & 16 & & & & \\
\hline Myxoid & 9 & & & & \\
\hline Pleomorphic & 3 & & & & \\
\hline Dedifferentiated & 2 & & & & \\
\hline Round cell & 1 & & & & \\
\hline Synovial sarcoma & 14 & 30.0 & & 12.6 & \\
\hline Monophasic & 6 & & & & \\
\hline Biphasic & 8 & & & & \\
\hline Leiomyosarcoma & 9 & 9.8 & & 9.4 & \\
\hline Epithelioid sarcoma & 5 & 16.1 & & 8.6 & \\
\hline Rhabdomyosarcoma & 3 & 39.4 & & 23.5 & \\
\hline Alveolar & 2 & & & & \\
\hline Embryonal & 1 & & & & \\
\hline
\end{tabular}

EZH2, enhancer of zeste homologue 2; LI, labeling index; NS, not significant.

curves for EZH2 and Ki-67 expression in the $36 \mathrm{MFHs} / \mathrm{UPSs}$, 31 liposarcomas and 14 synovial sarcomas. Among the histologic tumor types, overall survival was significantly worse in synovial sarcoma with a higher EZH2 LI than in those with a lower LI ( $\mathrm{P}=0.04)$. The same did not hold true for the Ki-67 LI. Additionally, there was no significant difference between
MFH/UPS or liposarcoma overall survival in the higher and lower EZH2 and Ki-67 LIs. We did not determine overall survival in patients with myxofibrosarcoma, leiomyosarcoma, epithelioid sarcoma and rhabdomyosarcoma, as the small number of cases did not allow for the required statistical analysis to be conducted. 



Figure 1. Representative immunoreactivity of EZH2 in soft tissue sarcoma. (A) MFH/UPS; (B) myxofibrosarcoma; (C) liposarcoma; (D) synovial sarcoma; (E) leiomyosarcoma; (F) epithelioid sarcoma; (G) rhabdomyosarcoma.

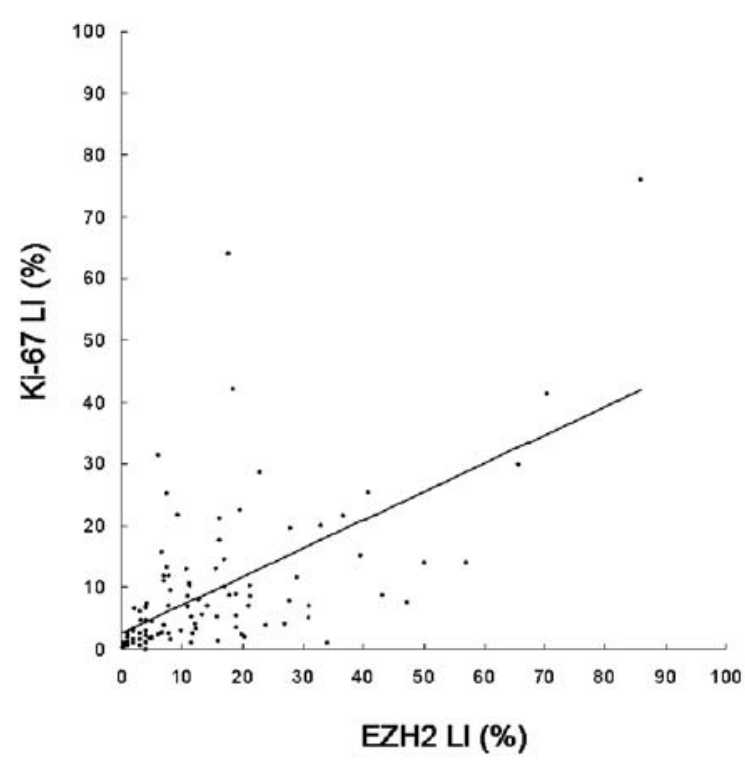

Figure 2. Correlation between the EZH2 and Ki-67 labeling indexes (LIs) in soft tissue sarcoma. There was a significant positive correlation between the LIs $(\mathrm{rs}=0.65 ; \mathrm{P}<0.01)$.

The Cox proportional hazards regression model was conducted adjusting for age ( $\geq 56$ or $<56$ years old), sex, tumor location (extremity or trunk), tumor size ( $\geq 5$ or $<5 \mathrm{~cm}$ ), histologic grade (1, 2 or 3$)$ and EZH2 and Ki-67 expression, It was not adjusted for distant metastasis, as this was not present at diagnosis but rather developed during follow-up. In multi-
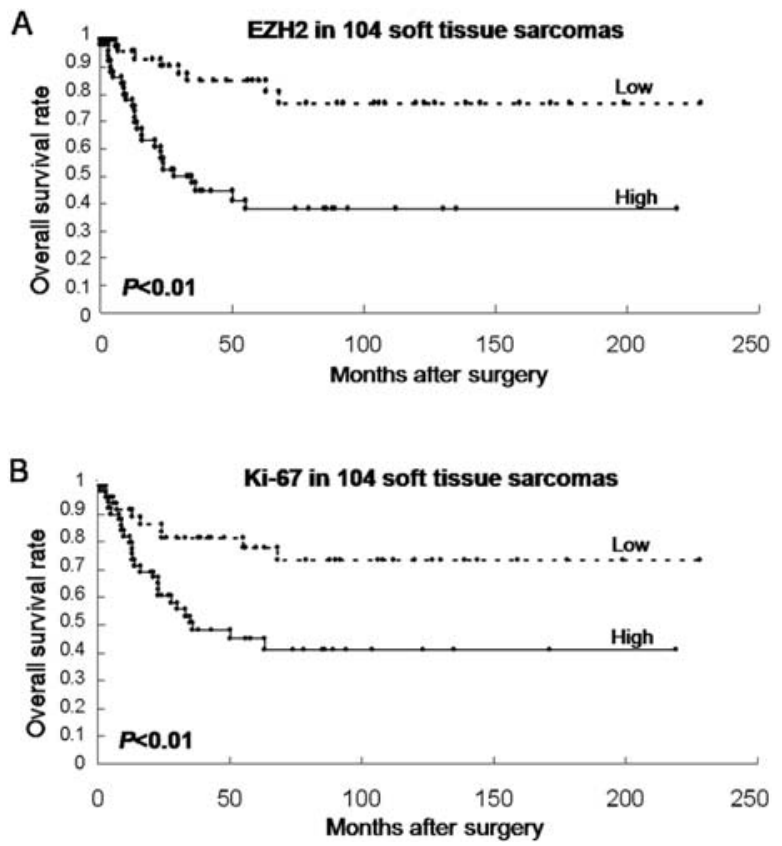

Figure 3. Kaplan-Meier survival curves for EZH2 (A) and Ki-67 (B) expression in soft tissue sarcoma. Patients with a higher EZH2 and Ki-67 labeling index had a significantly poorer prognosis.

variate analysis, high expression of EZH2, but not of Ki-67, and a histologic grade of 3 were identified as independent predictors of poor prognosis in the 104 soft tissue sarcomas (Table II). 

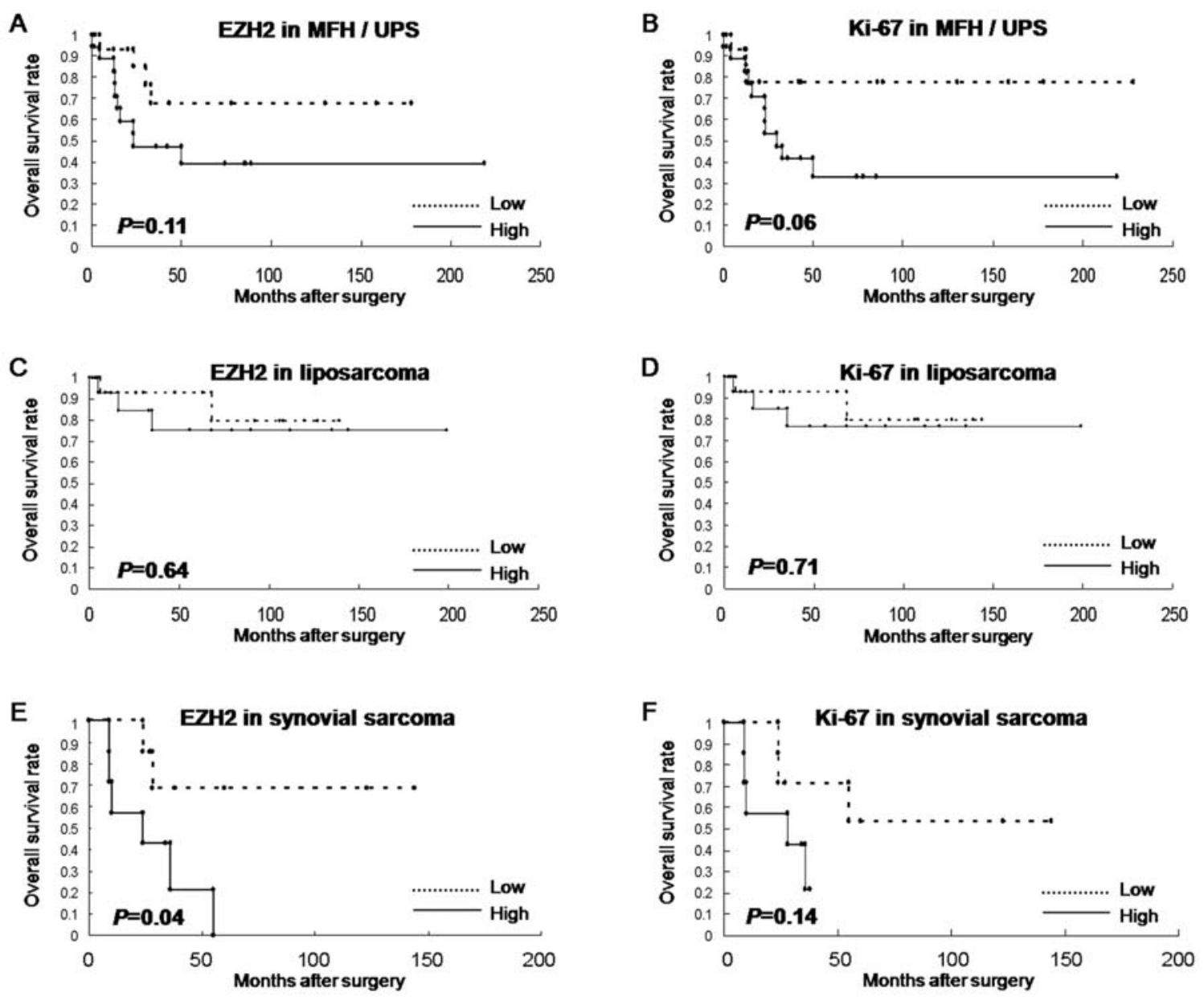

Figure 4. Kaplan-Meier survival curves for EZH2 and Ki-67 expression in individual histologic tumor types. (A) EZH2 in MFH/UPS; (B) Ki-67 in MFH/UPS; (C) EZH2 in liposarcoma; (D) Ki-67 in liposarcoma; (E) EZH2 in synovial sarcoma; (F) Ki-67 in synovial sarcoma.

Table II. Multivariate analysis of clinicopathological factors for overall survival in 104 patients with soft tissue sarcomas.

\begin{tabular}{lccc}
\hline Variables & Relative risk & P-value & $95 \% \mathrm{CI}$ \\
\hline $\begin{array}{l}\text { EZH2 expression } \\
\quad \text { Low }\end{array}$ & 1 & - & - \\
$\quad$ High & 2.79 & 0.02 & $1.2-6.5$ \\
Histologic grade & & & \\
$\quad$ Grade 1 & 1 & - & - \\
Grade 2 & 3.20 & 0.13 & $0.7-14.4$ \\
Grade 3 & 5.72 & 0.03 & $1.2-26.4$ \\
\hline
\end{tabular}

\section{Discussion}

Prognosis in patients with soft tissue sarcomas has improved due to diagnostic and therapeutic developments. A subset of soft tissue sarcomas, however, shows an aggressive clinical course and results in tumor-related mortality. Therefore, prognostic factors or markers are very important as they may help determine the course of adjuvant therapy and the length of follow-up. Tumor size, depth and histologic grade have been reported as being prognostic factors in soft tissue sarcomas (1-3). In addition to these factors, many proliferative and prognostic markers, such as Ki-67, PCNA, p53, P-gp, Rb, EGFR, survivin, TERT, cyclin A, AKT, FAS, hMSH protein, CD100, cyclin D1, VEGF, Glut-1, ß-catenin, p-glycoprotein, HIF-1 $\alpha$, CD44, EGF-1R and ezrin, have been studied in recent years (4-24).

EZH2, which is associated with malignancy in several cancers (30-41), might be a valuable marker of soft tissue sarcoma. Previous data have shown that EZH2 is specifically down-regulated in senescent fibroblasts, and that disruption of its expression retards cell proliferation and induces cell cycle arrest at the G2/M transition (44).

In the current study, immunohistochemistry was initially used to examine expression of EZH2 and Ki-67 in 104 soft tissue sarcomas, which was then correlated with clinicopathological factors. Our data reveal that expression was significantly more frequent in tumors with metastasis and high histologic grade. It has been demonstrated that EZH2 inhibits metastasis-suppressing genes, such as Rho GTPaseactivating protein 1 (30). Bake et al have reported that PSP94, which functions as a suppressor of tumor growth and metastasis, is down-regulated by EZH2 in human prostate cancer (45). These results suggest that EZH2 may actually inhibit metastasis-suppressing genes in soft tissue sarcoma, as has been demonstrated in prostate cancer (30). 
We have also demonstrated that the EZH2 LI is strongly correlated with that of Ki-67. Ki-67 antigen was first described in 1983 as a nuclear protein associated with cell proliferation (46). Thereafter, high expression of Ki-67 has been correlated with poor prognosis for patients with malignant tumors, including sarcomas (4-11). Currently, Ki-67 is commonly used as an excellent prognostic marker in soft tissue sarcoma. The present results suggest that EZH2 can be used in addition to Ki-67 as a proliferative and prognostic marker in soft tissue sarcoma.

The survival rate in our 104 patients was calculated by Kaplan-Meier analysis and revealed significant inverse correlations between prognosis and a higher EZH2 or Ki-67 LI. In fact, a higher EZH2 or Ki-67 LI was an adverse prognostic factor in patients with soft tissue sarcoma. As for histologic tumor type, the survival rate revealed a significant inverse correlation between prognosis and the EZH2 LI in synovial sarcoma only. However, the survival rate in other histologic tumor types was not significant. In certain of these, patients with a higher EZH2 or Ki-67 LI tended towards a worse prognosis than did those with lower LIs. This may be explained in part by the smaller number of patients with individual histologic tumor types. These results suggest that EZH2, as well as $\mathrm{Ki}-67$, is a useful prognostic marker in soft tissue sarcoma. However, it is difficult to compare which acts as the better prognostic marker in individual histologic tumor types.

Multivariate analysis revealed that high expression of EZH2 and a histologic grade of 3, but not high expression of $\mathrm{Ki}-67$, were independent prognostic factors of poor overall survival in soft tissue sarcoma. It has previously been reported that histologic grade is a prognostic factor $(1,3,47)$. Our data suggest that a high EZH2 LI may be a more useful prognostic marker than the Ki-67 LI in soft tissue sarcoma.

In summary, the present study indicates, perhaps for the first time, an association between EZH2 expression and clinicopathological factors, distant metastases and histologic grade, and suggests that a higher EZH2 LI could act as a useful prognostic marker of soft tissue sarcoma.

\section{Acknowledgements}

The authors thank Mr. N. Itaki, Ms. C. Yamasaki and Ms. M. Iwatani for their excellent technical assistance.

\section{References}

1. Stefanovski PD, Bidoli E, De Paoli A, et al: Prognostic factors in soft tissue sarcomas: a study of 395 patients. Eur J Surg Oncol 28: 153-164, 2002.

2. Lewis JJ, Leung D, Casper ES, Woodruff J, Hajdu SI and Brennan MF: Multifactorial analysis of long-term follow-up (more than 5 years) of primary extremity sarcoma. Arch Surg 134: 190-194, 1999.

3. Levine EA: Prognostic factors in soft tissue sarcoma. Semin Surg Oncol 17: 23-32, 1999

4. Ottaiano A, De Chiara A, Fazioli F, et al: Biological prognostic factors in adult soft tissue sarcomas. Anticancer Res 25: 4519-4526, 2005.

5. Engellau J, Bendahl PO, Persson A, et al: Improved prognostication in soft tissue sarcoma: independent information from vascular invasion, necrosis, growth pattern, and immunostaining using whole-tumor sections and tissue microarrays. Hum Pathol 36: 994-1002, 2005.

6. Engellau J: Prognostic factors in soft tissue sarcoma. Tissue microarray for immunostaining, the importance of whole-tumor sections and time-dependence. Acta Orthop Scand 75 (Suppl): 2 p preceding table, 2004.
7. Hasegawa T, Yokoyama R, Lee YH, Shimoda T, Beppu Y and Hirohashi S: Prognostic relevance of a histological grading system using MIB-1 for adult soft-tissue sarcoma. Oncology 58: 66-74, 2000 .

8. Tomita Y, Morooka T, Hoshida Y, et al: Reassessment of the 1993 Osaka grading system for localized soft tissue sarcoma in Japan. Anticancer Res 26: 4665-4669, 2006.

9. Hasegawa T, Yamamoto S, Yokoyama R, Umeda T, Matsuno Y and Hirohashi S: Prognostic significance of grading and staging systems using MIB-1 score in adult patients with soft tissue sarcoma of the extremities and trunk. Cancer 95: 843-851, 2002.

10. Jensen V, Sorensen FB, Bentzen SM, et al: Proliferative activity (MIB-1 index) is an independent prognostic parameter in patients with high-grade soft tissue sarcomas of subtypes other than malignant fibrous histiocytomas: a retrospective immunohistological study including 216 soft tissue sarcomas. Histopathology 32: 536-546, 1998.

11. Kroese MC, Rutgers DH, Wils IS, van Unnik JA and Roholl PJ: The relevance of the DNA index and proliferation rate in the grading of benign and malignant soft tissue tumors. Cancer 65 : 1782-1788, 1990.

12. Endo M, Tateishi U, Seki K, et al: Prognostic implications of glucose transporter protein-1 (glut-1) overexpression in bone and soft-tissue sarcomas. Jpn J Clin Oncol 37: 955-960, 2007.

13. Huuhtanen RL, Blomqvist CP, Bohling TO, et al: Expression of cyclin A in soft tissue sarcomas correlates with tumor aggressiveness. Cancer Res 59: 2885-2890, 1999.

14. Musella M, Fazioli F, Lombardi S, et al: Assessment of cyclin D1 overexpression as a prognostic factor in soft tissue sarcomas: role of laparoscopy and core needle biopsy. Surg Endosc 19: 1120-1124, 2005.

15. Ch'ng E, Tomita Y, Zhang B, et al: Prognostic significance of CD100 expression in soft tissue sarcoma. Cancer 110: 164-172, 2007.

16. Shintani K, Matsumine A, Kusuzaki K, et al: Expression of hypoxia-inducible factor (HIF)-1alpha as a biomarker of outcome in soft-tissue sarcomas. Virchows Arch 449: 673-681, 2006.

17. Sato O, Wada T, Kawai A, et al: Expression of epidermal growth factor receptor, ERBB2 and KIT in adult soft tissue sarcomas: a clinicopathologic study of 281 cases. Cancer 103: 1881-1890, 2005.

18. Ahlen J, Wejde J, Brosjo O, et al: Insulin-like growth factor type 1 receptor expression correlates to good prognosis in highly malignant soft tissue sarcoma. Clin Cancer Res 11: 206-216, 2005.

19. Tomita Y, Morooka T, Hoshida Y, et al: Prognostic significance of activated AKT expression in soft-tissue sarcoma. Clin Cancer Res 12: 3070-3077, 2006

20. Weng WH, Ahlen J, Astrom K, Lui WO and Larsson C: Prognostic impact of immunohistochemical expression of ezrin in highly malignant soft tissue sarcomas. Clin Cancer Res 11: 6198-6204, 2005.

21. Peiper M, Sato T, Zurakowski D, et al: CD44s expression is associated with improved survival in soft tissue sarcoma. Anticancer Res 24: 1053-1056, 2004.

22. Takahiro T, Shinichi K and Toshimitsu S: Expression of fatty acid synthase as a prognostic indicator in soft tissue sarcomas. Clin Cancer Res 9: 2204-2212, 2003.

23. Taubert HW, Bartel F, Kappler M, et al: Reduced expression of hMSH2 protein is correlated to poor survival for soft tissue sarcoma patients. Cancer 97: 2273-2278, 2003.

24. Kappler M, Kotzsch M, Bartel F, et al: Elevated expression level of survivin protein in soft-tissue sarcomas is a strong independent predictor of survival. Clin Cancer Res 9: 1098-1104, 2003.

25. Yamashita H, Osaki M, Ardyanto TD, Osaki M, Yoshida H and Ito $\mathrm{H}$ : Cyclooxygenase-2 in human malignant fibrous histiocytoma: correlations with intratumoral microvessel density, expression of vascular endothelial growth factor and thymidine phosphorylase. Int J Mol Med 14: 565-570, 2004

26. Sato T, Peiper M, Heinecke A, et al: Expression of HER2/neu does not correlate with survival in soft tissue sarcoma. Onkologie 26: 268-271, 2003.

27. Osaki M, Osaki M, Yamashita H, Shomori K, Yoshida H and Ito $\mathrm{H}$ : Expression of minichromosome maintenance-2 in human malignant fibrous histiocytomas: correlations with Ki-67 and P53 expression, and apoptosis. Int J Mol Med 10: 161-168, 2002.

28. Yu J, Yu J, Rhodes DR, et al: A polycomb repression signature in metastatic prostate cancer predicts cancer outcome. Cancer Res 67: 10657-10663, 2007. 
29. Chen H, Rossier C and Antonarakis SE: Cloning of a human homolog of the Drosophila enhancer of zeste gene (EZH2) that maps to chromosome 21q22.2. Genomics 38: 30-37, 1996.

30. Varambally S, Dhanasekaran SM, Zhou M, et al: The polycomb group protein EZH2 is involved in progression of prostate cancer. Nature 419: 624-629, 2002.

31. Kleer CG, Cao Q, Varambally S, et al: EZH2 is a marker of aggressive breast cancer and promotes neoplastic transformation of breast epithelial cells. Proc Natl Acad Sci USA 100: 11606-11611, 2003.

32. Raaphorst FM, van Kemenade FJ, Blokzijl T, et al: Coexpression of BMI-1 and EZH2 polycomb group genes in Reed-Sternberg cells of Hodgkin's disease. Am J Pathol 157: 709-715, 2000.

33. Ding L and Kleer CG: Enhancer of Zeste 2 as a marker of preneoplastic progression in the breast. Cancer Res 66: 9352-9355, 2006.

34. Bachmann IM, Halvorsen OJ, Collett K, et al: EZH2 expression is associated with high proliferation rate and aggressive tumor subgroups in cutaneous melanoma and cancers of the endometrium, prostate and breast. J Clin Oncol 24: 268-273, 2006.

35. Arisan S, Buyuktuncer ED, Palavan-Unsal N, Caskurlu T, Cakir OO and Ergenekon E: Increased expression of EZH2, a polycomb group protein, in bladder carcinoma. Urol Int 75: 252-257, 2005.

36. Weikert S, Christoph F, Kollermann J, et al: Expression levels of the EZH2 polycomb transcriptional repressor correlate with aggressiveness and invasive potential of bladder carcinomas. Int J Mol Med 16: 349-353, 2005.

37. Raman JD, Mongan NP, Tickoo SK, Boorjian SA, Scherr DS and Gudas LJ: Increased expression of the polycomb group gene, EZH2, in transitional cell carcinoma of the bladder. Clin Cancer Res 11: 8570-8576, 2005.

38. Matsukawa Y, Semba S, Kato H, Ito A, Yanagihara K and Yokozaki H: Expression of the enhancer of zeste homolog 2 is correlated with poor prognosis in human gastric cancer. Cancer Sci 97: 484-491, 2006.
39. Mattioli E, Vogiatzi P, Sun A, et al: Immunohistochemical analysis of pRb2/p130, VEGF, EZH2, p53, p16(INK4A), p27(KIP1), p21(WAF1), Ki-67 expression patterns in gastric cancer. J Cell Physiol 210: 183-191, 2007.

40. Raaphorst FM, Meijer CJ, Fieret E, et al: Poorly differentiated breast carcinoma is associated with increased expression of the human polycomb group EZH2 gene. Neoplasia 5: 481-488, 2003.

41. Visser HP, Gunster MJ, Kluin-Nelemans HC, et al: The Polycomb group protein EZH2 is upregulated in proliferating, cultured human mantle cell lymphoma. Br J Haematol 112: 950-958, 2001.

42. Fletcher CDM, Unni KK and Mertens F: World Health Organization Classification of Tumours. Pathology and Genetics of Tumours of Soft tissue and Bone. IARC Press, Lyon, 2002.

43. Guillou L, Coindre JM, Bonichon F, et al: Comparative study of the National Cancer Institute and French Federation of Cancer Centers Sarcoma Group grading systems in a population of 410 adult patients with soft tissue sarcoma. J Clin Oncol 15: 350-362, 1997.

44. Tang X, Milyavsky M, Shats I, Erez N, Goldfinger N and Rotter V: Activated p53 suppresses the histone methyltransferase EZH2 gene. Oncogene 23: 5759-5769, 2004.

45. Beke L, Nuytten M, van Eynde A, Beullens M and Bollen M: The gene encoding the prostatic tumor suppressor PSP94 is a target for repression by the Polycomb group protein EZH2. Oncogene 26: 4590-4595, 2007.

46. Gerdes J, Schwab U, Lemke H and Stein H: Production of a mouse monoclonal antibody reactive with a human nuclear antigen associated with cell proliferation. Int $\mathrm{J}$ Cancer 31 : 13-20, 1983.

47. Coindre JM: Grading of soft tissue sarcomas: review and update. Arch Pathol Lab Med 130: 1448-1453, 2006. 